\title{
DA PRESERVAÇÃO À RESTAURAÇÃO: POLÍTICAS E MÉTODOS APLICADOS AOS JARDINS HISTÓRICOS
}

\author{
FROM PRESERVATION TO RESTORATION: \\ POLICIES AND METHODS APPLIED TO HISTORIC GARDENS
}

\section{Marianna Gomes Pimentel Cardoso*}

\section{RESUMO}

presente artigo aborda a questão do tratamento dos jardins históricos no âmbito patrimonial internacional e nacional tanto nas políticas patrimoniais quanto nas metodologias de restauração/intervenção nos mesmos. Objetivando expor um panorama de como o jardim foi abordado no domínio do patrimônio e apontar questionamentos atualizados, em um primeiro momento centra-se nas políticas patrimoniais, versando sobre as transformações do conceito de jardim histórico, inicialmente vinculado à noção de monumento e hoje convergindo para o conceito de paisagem cultural. Discute-se também a classificação do jardim pelo Instituto Nacional do Patrimônio Histórico e Artístico Nacional (Iphan) tanto o tombamento como nos instrumentos de proteção. Finalmente analisam-se os métodos de restauro dos jardins ressaltando suas especificidades por meio de estudo comparativo de duas metodologias específicas: uma internacional, publicada pelo Comitê Internacional dos Jardins Históricos (ICOMOS-IFLA), de Carmen Añón (1989), e outra nacional, de Carlos Delphim (2005), adotada pelo Iphan.

Palavras-chave: Patrimônio cultural. Jardins. Patrimônio paisagístico. Restauração.

\section{ABSTRACT}

This article discusses the issue of treatment of the historic garden in the international and national heritage scenario, both in its heritage policies as well as in its methodologies for restoration/intervention. With the objective of presenting an overview of how the garden issue has been approached in the heritage area and pointing out updated questions, at first, it focuses on heritage policies, showing the transformations in the concept of historic garden, initially linked to the notion of monument and now currently converging to the concept of cultural landscape. It also discusses the classification system of the garden drawn up at the National Institute of Historical and Artistic Heritage (Iphan), concerning its listing as well as the instruments of protection. Finally, it analyzes the specific restoration methods for gardens, drawing attention to their specificities through a comparative study of two specific methodologies, an international methodology, published by the International Committee for Historic Gardens (ICOMOS-IFLA) authored by Carmen Añon (1989) and the other, a national one, by Carlos Delphim (2005), adopted by Iphan.

Keywords: Cultural heritage. Gardens. Landscape heritage. Restoration.

Graduada em Arquitetura e Urbanismo pela Universidade de Brasília (UnB). Mestre em Teoria e História pelo Programa de Pós-Graduação em Arquitetura e Urbanismo da UnB (PPG-FAU). Professora assistente do curso de Arquitetura e Urbanismo da Universidade Federal do Tocantins (UFT). Doutoranda na École doctorale Sciences humaines et sociales, Perspectives européennes (ED SHS-PE) na Université de Strasbourg (França).

CV: http://lattes.cnpq.br/1321544210745339 


\section{INTRODUÇÃO}

Para Cauquelin (2007) é por meio da separação da natureza que o jardim se constituiu: "Eis a longa teoria dos jardins, kepos-hortus, lugares de repouso e de meditação, que ao romper com o espaço indeterminado ou superinvestido de marcas por e para uma história, constroem seus traços distintivos longe da cidade". (CAUQUELIN, 2007, p. 13). Assim, como produto humano, o jardim assume características comuns a outras formas de expressão, conectando-se com o formato superior das expressões artísticas.

O jardim é, segundo Fariello (2008), uma composição estética que pode assumir o valor de uma obra de arte, uma vez que na arte do jardim repetem-se certos princípios compositivos e de ordenação que "[...] apresentam uma estreita analogia porque têm sua origem e seu fundamento nas leis misteriosas do universo que se revelam na harmonia das relações musicais e em determinadas combinações de formas, espaço e cores". (FARIELLO, 2008, p. 10-11). Mas um jardim também pode ser considerado como um documento e mostrar "[...] vestígios sobre as origens e evolução do homem, e que, portanto, forma parte indiscutível das raízes que dão identidade aos povos". (BERTRUY, 2009, p. 323). Além de inegável valor artístico, as obras paisagísticas possuem importância documental, fruto do posicionamento do homem diante da natureza e do momento histórico em que vive.

O reconhecimento dos valores artísticos e históricos dos jardins fez com que fossem apropriados pelas políticas patrimoniais em todo o mundo. Buscando compreender a forma como foram tratados pela ótica patrimonial, este artigo visa à exposição das diferentes abordagens do objeto "jardim" nesse contexto. Para tanto o presente trabalho' estrutura-se em três partes. A primeira dedica-se a mostrar diacronicamente as transformações do conceito de patrimônio paisagístico, concentrando-se nos jardins históricos - primeiramente vistos como monumento e hoje convergindo para o conceito de paisagem cultural. Investigam-se as principais recomendações, cartas e documentos que envolvem a atribuição patrimonial aos jardins considerados dignos de algum tipo de proteção e evidencia-se o papel desempenhado por instituições internacionais².

Internacionalmente essa reflexão destaca as discussões do tema em vários documentos, como a Carta de Atenas (1931), a Carta de Veneza (1964), a criação do Departamento de Jardins Históricos (IFLA, 1964), o Simpósio sobre Jardins Históricos em Fontainebleau (1971), a Carta de Florença (1981) e a inserção do jardim numa nova abordagem, a Paisagem Cultural.

Num segundo momento a questão centra-se em explorar como os jardins históricos são abordados no caso nacional pelo Instituto do Patrimônio Histórico e Artístico Nacional (Iphan). Evidenciam-se tanto as políticas patrimoniais (Carta de Bagé, 2007;

Parte das análises apresentadas foram objeto da pesquisa de mestrado $O$ jardim como patrimônio: a obra de Burle Marx em Brasília, defendida em 2012 na Universidade de Brasília (UnB) no Programa de Pós-Graduação em Arquitetura e Urbanismo, sob a orientação da professora doutora Elane Ribeiro Peixoto. Alterações e atualizações foram elaboradas para o presente artigo.

2 Organização das Nações Unidas para a Educação, a Ciência e a Cultura (UNESCO), Conselho Internacional de Monumentos e Sítios (ICOMOS) e Comité Internacional dos Jardins Históricos (ICOMOS-IFLA). 
Carta da Serra da Bodoquena, 2009; a Chancela da Paisagem Cultural Brasileira, 2009; a Carta dos Jardins Históricos Brasileiros, 2010) quanto questionamentos relativos ao tombamento, mais especificamente questionamentos relativos à classificação e inscrição dos jardins históricos brasileiros nos Livros do Tombo e como o jardim é entendido por esta instituição.

Por fim problematiza-se o tema da restauração dos jardins, comparando duas metodologias ${ }^{3}$ de restauro, uma elaborada por Carmen Añón, divulgada pelo Comité Internacional dos Jardins Históricos (ICOMOS-IFLA) em 1989 e outra de autoria de Carlos Delphim, intitulada "Manual de Intervenções em Jardins Históricos" e publicada pelo Iphan em 2005.

\section{O JARDIM HISTÓRICO E O PATRIMÔNIO: UM PROCESSO EM CONSTRUÇÃO}

A inclusão de uma perspectiva cultural na historiografia resultou na reformulação do conceito de patrimônio com abordagens além da história política e social, incorporando os valores culturais e as dimensões simbólicas que envolvem as inúmeras práticas e atividades humanas, surgindo então o termo "patrimônio cultural"4. Nesse momento a ampliação da abordagem do campo de patrimônio nas discussões nacionais e internacionais leva à inserção do termo jardim histórico, uma vez que, como afirma Bertruy (2009), os jardins históricos são considerados testemunhos da arte, da história e da cultura da humanidade e, dessa forma, parte do patrimônio de uma sociedade.

Marcondes (2009) sublinha que mesmo sendo importante legado histórico e cultural o tema dos jardins nas primeiras discussões sobre o patrimônio estava muito associado aos monumentos que seriam preservados. Na recomendação da Carta de Atenas de 1931, por exemplo, o terceiro tópico da seção Conclusões Gerais - "A Valorização dos Monumentos" - ressalta a importância de estudar "[...] as plantações e ornamentações vegetais convenientes a determinados conjuntos de monumentos para the conservar o caráter antigo". (Iphan, 2004, p. 14). Mesmo reconhecendo seu valor, percebe-se que a Carta de Atenas de 1931 delega ao jardim um papel secundário, valorizando mais o monumento emoldurado por ele.

Em 1964 a Carta de Veneza, resultado do II Congresso Internacional de Arquitetos e de Técnicos de Monumentos Históricos realizado em Veneza de 25 a 31 de maio de 1964, estabelece diretrizes sobre conservação e restauração de monumentos e sítios. Define no artigo 1: "A noção de monumento histórico engloba a criação arquitetônica isolada, bem como o sítio, rural ou urbano, que constitua testemunho de uma civilização particular, de uma evolução significativa ou de um acontecimento

\footnotetext{
3 Metodologia entendida como conjunto de procedimentos necessário para a preservação dos jardins históricos.

4 Choay (2011) alerta que o termo acompanhado do adjetivo cultural foi lançado na França em 1959 por André
} Malraux ao tornar-se Ministro de Estado da Cultura. 
histórico." (CARTA DE VENEZA, 1964)5. Nota-se nessa Carta um maior interesse em obras referentes à paisagem, mas as discussões a respeito da conservação e restauro ainda são incipientes. Contudo a maior importância dessa Carta é o fato de permanecer como documento base do ICOMOS, órgão consultor administrado pela United Nations Educational, Scientific and Cultural Organization (UNESCO) criado em 1965.

De igual importância para a preservação dos jardins é a união do ICOMOS com a International Federation of Landscape Architects (IFLA). Segundo Beriman (2011), esta organização foi fundada em 1948 por Sir Geofrey Jellicoe e René Pechère com o apoio de quinze países europeus. Marcke descreve:

[...] durante a Assembleia Geral da IFLA, na Sardenha, em 1968, foi criada uma Comissão de Jardins e Sítios Históricos, cuja responsabilidade foi atribuída a René Pechère [...] com a ajuda de uma colega alemã, Gerda Gollwitzer, preparou uma lista de jardins históricos em todo o mundo. Eles ficaram surpresos ao descobrir que eles eram apenas 2.000, o que era muito pouco comparado com monumentos históricos! Entenderam que era necessário expandir as fontes de informação e criar uma equipe que não incluísse somente os arquitetos paisagistas, mas os historiadores, arquitetos, arqueólogos, botânicos. Foi, então, quando René Pechère recorreu ao professor Raymond Lemaire, então Secretário Geral do ICOMOS, e ao seu Presidente, Piero Gazzola. Depois de meses [...] foi encarregado de começar a organizar, com a colaboração logística do ICOMOS, uma conferência a cada dois anos, e de criar um comitê misto com a IFLA. (MARCKE, s/d, p. 2 e 3$)^{6}$.

A parceria desses dois órgãos consultivos - ICOMOS-IFLA - por meio de conferências tem guiado as principais discussões sobre preservação e intervenção dos jardins históricos em todo o mundo. A primeira conferência aconteceu de 13 a 18 de setembro de 1971 no Château de Fontainebleau (França), que discutiu entre outros assuntos as principais ameaças aos jardins, como crescimento desordenado das grandes cidades, polvição, mudanças no modo de vida, ausência de legislação específica e descontrole das visitações nessas áreas. Essa reunião também foi responsável pela definição do conceito de jardim histórico: "[...] uma composição arquitetônica e hortícola de interesse para o público do ponto de vista histórico e artístico". (ICOMOS, 1993, p. 41).

A preocupação exclusiva com a preservação dos jardins é abordada por uma carta patrimonial, a Carta de Florença, somente no início da década de 1980 na tentativa de complementar a Carta de Veneza de 1964. Assim, a Carta de Florença de 1981 caracteriza o jardim histórico da mesma forma que a definição proposta pelo encontro

Disponível em: <www.icomos.org/charters/Venice\%20Charter\%20-\%20Portuguese.DOC>. Acesso em: 20 jul. 2016.

6 Tradução de Marianna Gomes Pimentel Cardoso.

$7 \quad$ La UNESCO y la fuerza del interés en paisajes vista actualmente en el más alto nivel, llevó al Comité a proponer un cambio de nombre agregando Paisajes Culturales: Comité Internacional de Jardines-Paisajes Culturales ICOMOS-IFLA. Esto fue en Aranjuez el 23 de septiembre de 1998. 
em Fontainebleau: "Artigo 1: Um jardim histórico é uma composição arquitetônica e vegetal que do ponto de vista da história ou da arte apresenta um interesse público. Como tal é considerado monumento." (Iphan, 2004, p. 253). $\bigcirc$ artigo $5^{\circ}$ afirma ainda que o jardim é:

[...] expressão de relações estreitas entre a civilização e a natureza, lugar de deleite, apropriado à meditação e ao devaneio, o jardim adquire o sentido cósmico de uma imagem idealizada do mundo, um paraíso no sentido etimológico do termo, mas que dá testemunho de uma cultura, de um estilo, de uma época e, eventualmente, da originalidade de um criador artístico. (Iphan, 2004, p. 254).

A inegável importância que o jardim histórico ganhou nos últimos anos do século $X X$ proporcionou aumento significativo nas discussões sobre o tema. Em consequência, a classificação de "monumento" não é mais utilizada pelos pesquisadores do tema. De acordo com Beriman (2001), o conceito de jardim histórico "evolviu", sendo atualmente tratado como uma categoria das paisagens culturais, por ser uma paisagem da natureza modificada pelo homem. O jardim histórico passou a ser classificado, então, como um tipo de paisagem cultural. $O$ conceito de paisagem cultural tem suas origens na $17^{a}$ sessão da Conferência Geral da UNESCO (1972), em que se promoveu a Convenção sobre a Proteção do Patrimônio Cultural e Natural. Na concepção de Araújo (2009):

[...] seria então nesse ano que se lançariam "os primeiros esforços para a conservação do patrimônio cultural e natural, frente à constatação das crescentes ameaças de destruição, surgidas não apenas em função de "causas tradicionais", mas também pelas transformações sociais e econômicas por que passava o mundo. (ARAÚJO, 2009).

Nessa Convenção foi feita uma distinção entre patrimônio cultural e natural a fim de estabelecer posteriormente políticas específicas para cada tipo de bem patrimonial. Além disso, a Convenção de 1972 teve fundamental importância para criar os parâmetros de inscrição de bens na Lista do Patrimônio Mundial e na Lista do Patrimônio Mundial em Perigo.

Pode-se concluir que as obras paisagísticas estão mais ligadas ao caráter cultural que ao natural, porque, mesmo utilizando-se de elementos da natureza em suas composições, são manifestações do savoir-faire humano. É importante ressaltar, todavia, que a questão da paisagem na atualidade ${ }^{8}$ é tratada de forma interdisciplinar, não se restringindo apenas aos ambientes naturais. Vieira afirma que o estudo da paisagem tem uma abordagem que:

8 Conceito de paisagem se transforma ao longo da história, e para evitar um equívoco anacrônico frisam-se as temporalidades do que se entende por paisagem. Cauquelin (2007) na obra "A invenção da paisagem" expõe que no período da renascença italiana a paisagem tinha uma estreita relação com a prática pictórica e que atualmente o significado da paisagem engloba tanto as diferentes abordagens da natureza quanto a dialética do real e da imagem no mundo contemporâneo, introduzindo a ideia de paisagens virtuais. 
[...] da pintura de paisagens (um capítulo da história da arte) e do paisagismo (parte incorporada à arquitetura e urbanismo), o tema extrapolou para a geografia (seja física ou humana), para a ecologia (por conta do movimento ambientalista), para a história, para os estudos de cinema, e também para o turismo e a literatura, pois já se estuda a paisagem a partir de relatos de viajantes, e dos guias de viagens. De tão amplo que é o tema, o uso do termo extrapolou os territórios desses saberes, e hoje, o vocábulo transformou-se numa metáfora, quando se quer situar num panorama qualquer assunto sobre o qual se queira discorrer. (VIEIRA, 2006, p. 2).

No contexto da prática preservacionista, a Convenção do Patrimônio Mundial de 1992, realizada em Santa Fé no México, adotou um novo conceito para a classificação dos bens: a paisagem cultural. Ribeiro destaca que, segundo o relatório elaborado nessa Convenção, as paisagens:

[...] são consideradas ilustrativas da evolução da sociedade humana e seus assentamentos ao longo do tempo, sobre a influência de contingências físicas e/ou oportunidades apresentadas pelo ambiente natural, bem como pelas sucessivas forças social, econômica e cultural, que nelas interferem. Elas deveriam ser selecionadas pelo seu valor universal e pela sua representatividade em termos de uma região geocultural claramente definida e também pela sua capacidade de ilustrar elementos culturais essenciais e distintos dessa região. (RIBEIRO, 2007, p. 41).

Conforme comenta Castriota, a Convenção do Patrimônio Mundial de 1992 foi o primeiro instrumento legal internacional a reconhecer e proteger esse tipo complexo de patrimônio: a paisagem cultural, "[...] focada na interação entre natureza e cultura e, ao mesmo tempo, ligada também intimamente às maneiras tradicionais de viver". (CASTRIOTA, 2009, p. 12). Foram elaborados três grupos para a classificação das paisagens culturais, como descrito na tabela 1.

Tabela 1 Tabela indicando a classificação das Paisagens Culturais pela UNESCO

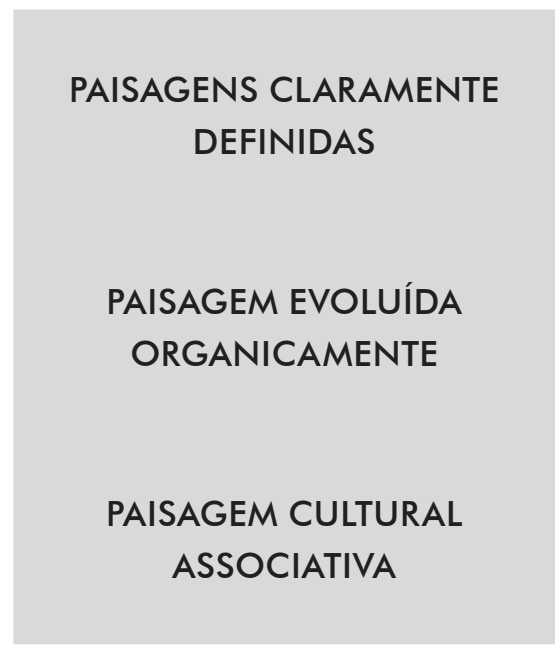

São aquelas desenhadas e criadas intencionalmente, nas quais se encaixam jardins e parques construídos por razões estéticas.

Resulta de um imperativo inicial social, econômico, administrativo e/ou religioso e desenvolveu sua forma atual através da associação com seu meio natural e em resposta ao mesmo.

Fonte: Produzida por Marianna Gomes Pimentel Cardoso - adaptada de Ribeiro (2007). 
Os jardins históricos são classificados como "Paisagens claramente definidas", pois expressam as manifestações culturais e estéticas de um povo e/ou período na paisagem. Essa atribuição evidencia uma tendência atual no âmbito internacional para incluir os jardins históricos na globalidade da paisagem cultural. Em contrapartida, dado o fato de a discussão ser recente, inclina-se a deduzir que a definição de jardim histórico aparece ainda como um conceito em transformação, cujo caráter monumental cede cada vez mais lugar à abordagem culturalista.

\section{INSTRUMENTOS DE PROTEÇÃO APLICADOS AOS JARDINS HISTÓRICOS NO BRASIL}

Até o presente ano (2016), há importantes recomendações, detalhadas a seguir, que auxiliam na preservação dos jardins brasileiros, mas a respeito do tombamento 9 - Iphan, desde sua criação na década de 1930, classifica os jardins históricos entre os quatro Livros do Tombo ${ }^{10}$ no Livro Arqueológico, Etnográfico e Paisagístico. Entretanto, ao analisar de forma aprofundada a inscrição dos jardins nos Livros do Tombo, percebe-se que são poucos os jardins históricos independentes, ou seja, dissociados de conjuntos arquitetônicos e urbanísticos ou de paisagens naturais.

Em levantamento realizado no Arquivo Noronha Santos e na mais detalhada Lista de Bens Tombados e Processos em Andamento (1938-2015), disponível na página oficial do Iphan, verifica-se uma diversidade na inscrição do bem "jardim histórico", sendo a maior parte parques. Percebe-se ainda que em alguns casos os jardins estão inscritos no Livro Histórico ou no de Belas Artes ou em mais de um Livro, como explícito na tabela 2.

A seleção analisada na referida lista" apresenta alguns jardins associados a conjuntos arquitetônicos tombados, como o Solar Grandjean de Montigny e jardim, a Casa Modernista de Warchavchik na rua Santa Cruz - conjunto constituído pela casa, o jardim e o bosque que o circundam -, o Palacete do Benfica, compreendendo o terreno, o palacete, o jardim e demais construções nele existentes e o Jardim e Morro do Valongo, conjunto arquitetônico e paisagístico. Todos também estão inscritos de forma desigual nos Livros.

9 Forma de proteção regida pelo Decreto-Lei Federal n 25 de 30 de novembro de 1937. Organiza a proteção do patrimônio histórico e artístico nacional. Diário Oficial da União, 6 dez. 1937, p. 24056.

10 patrimônio material é classificado pelo Iphan como conjunto de bens culturais que segue uma classificação segundo os quatro Livros do Tombo: Arqueológico, Paisagístico e Etnográfico; Histórico; das Belas Artes; das Artes Aplicadas.

11 Cabe salientar que há também a categoria "Paisagem" e a denominação de "conjuntos paisagísticos", que em geral se referem ao patrimônio natural/ambiental - como serras e morros - e que algumas vezes se associam a conjuntos urbanos tombados. 
Tabela 2 Tabela indicando os Jardins Históricos Brasileiros inscritos nos Livros do Tombo.

\begin{tabular}{|c|c|c|c|c|c|c|c|c|}
\hline UF & Classificação & $\begin{array}{l}\text { Ano de } \\
\text { Abertura }\end{array}$ & $\mathrm{N}^{\circ}$ & Nome atribuído & $\begin{array}{c}\text { Livro } \\
\text { Arqueológico } \\
\text { Etnográfico e } \\
\text { Paisagístico }\end{array}$ & $\begin{array}{l}\text { Livro } \\
\text { Histórico }\end{array}$ & $\begin{array}{l}\text { Livro } \\
\text { Belas } \\
\text { Artes }\end{array}$ & $\begin{array}{c}\text { Artes } \\
\text { Aplicadas }\end{array}$ \\
\hline RJ & $\begin{array}{l}\text { Jardim } \\
\text { Histórico }\end{array}$ & 1938 & 99 & $\begin{array}{l}\text { Passeio Público: } \\
\text { chafariz dos } \\
\text { Jacarés, obeliscos } \\
\text { e Portão do } \\
\text { Mestre Valentim }\end{array}$ & & Jun-38 & Jun-38 & \\
\hline RJ & $\begin{array}{l}\text { Jardim } \\
\text { Histórico }\end{array}$ & 1938 & 157 & $\begin{array}{c}\text { Jardim Botânico } \\
\text { (especificamente o } \\
\text { Portão da Antiga } \\
\text { Fábrica de Pólvora } \\
\text { e o Pórtico da } \\
\text { Antiga Academia } \\
\text { Imperial de Belas } \\
\text { Artes) } \\
\end{array}$ & Mai-38 & & & \\
\hline BA & $\begin{array}{l}\text { Jardim } \\
\text { Histórico }\end{array}$ & 1939 & 202 & $\begin{array}{l}\text { Hospital São João } \\
\text { de Deus: jardim }\end{array}$ & Jul-40 & & & \\
\hline PE & $\begin{array}{l}\text { Jardim } \\
\text { Histórico }\end{array}$ & 1953 & 523 & $\begin{array}{l}\text { Campos das } \\
\text { batalhas de } \\
\text { Guararapes, atual } \\
\text { Parque Histórico } \\
\text { Nacional dos } \\
\text { Guararapes }\end{array}$ & & Out-61 & & \\
\hline RJ & $\begin{array}{l}\text { Jardim } \\
\text { Histórico }\end{array}$ & 1957 & 537 & $\begin{array}{l}\text { Parque Henrique } \\
\text { Lage (Conjunto } \\
\text { Paisagístico) }\end{array}$ & & Jun-57 & & \\
\hline RJ & $\begin{array}{l}\text { Jardim } \\
\text { Histórico }\end{array}$ & 1961 & 633 & $\begin{array}{l}\text { Horto Florestal: } \\
\text { conjunto } \\
\text { arquitetônico } \\
\end{array}$ & Dez-73 & & & \\
\hline CE & $\begin{array}{l}\text { Jardim } \\
\text { Histórico }\end{array}$ & 1964 & 744 & $\begin{array}{c}\text { Área do Passeio } \\
\text { Público, Antiga } \\
\text { Praça dos Mártires }\end{array}$ & Abr-65 & & & \\
\hline RJ & $\begin{array}{l}\text { Jardim } \\
\text { Histórico }\end{array}$ & 1964 & 748 & $\begin{array}{l}\text { Aterro do } \\
\text { Flamengo } \\
\end{array}$ & Jul-65 & & & \\
\hline SC & $\begin{array}{l}\text { Jardim } \\
\text { Histórico }\end{array}$ & 1965 & 754 & $\begin{array}{c}\text { Parque à rua } \\
\text { Marechal } \\
\text { Deodoro, } 365 \\
\end{array}$ & Abr-65 & & & \\
\hline RJ & $\begin{array}{l}\text { Jardim } \\
\text { Histórico }\end{array}$ & 1984 & 1131 & $\begin{array}{l}\text { Sítio Roberto } \\
\text { Burle Marx e } \\
\text { sua coleção } \\
\text { museológica e } \\
\text { bibliográfica }\end{array}$ & Ago-03 & & Ago-03 & \\
\hline PA & $\begin{array}{l}\text { Jardim } \\
\text { Histórico }\end{array}$ & 1989 & 1.297 & $\begin{array}{c}\text { Parque } \\
\text { Zoobotânico do } \\
\text { Museu Paraense } \\
\text { Emílio Goeldi }\end{array}$ & Jan-94 & Jan-94 & & \\
\hline BA & $\begin{array}{l}\text { Jardim } \\
\text { Histórico }\end{array}$ & 1989 & 1.289 & $\begin{array}{c}\text { Parque e Fonte do } \\
\text { Queimado }\end{array}$ & & Fev-97 & & \\
\hline
\end{tabular}

Fonte: Produzida por Marianna Gomes Pimentel Cardoso com dados da Lista de Bens Tombados e Processos em Andamento (1938-2015). Disponível em: <http://portal.iphan.gov.br/pagina/detalhes/126>, sob título "Bens tombados". Acesso em: 2 fev. 2016. 
As várias classificações nos Livros e o tratamento não uniforme desse bem podem ser atribuídos a dois motivos principais. Destaca-se em primeiro lugar a menor autonomia do jardim em relação ao bem arquitetônico ou urbanístico, mostrando uma política que valoriza o trabalho da arquitetura, a edificação em si como obra maior, subjugando os jardins a uma complementação do bem arquitetônico (tal qual pregava a Carta de Atenas em 1931). Ressalta-se ainda a pouca quantidade de jardins protegidos e a ausência de jardins de escalas menores, já que predominam na lista os jardins de macroescala como parques e hortos.

O outro motivo atribui-se à duplicidade do jardim: ser um sistema vivo, vinculado às relações da natureza e, ao mesmo tempo, uma expressão cultural e artística humana, inserida num contexto histórico. Essa característica "dupla" dificulta a categorização no modelo atual, ou seja, inscrevê-lo apenas no Livro Arqueológico, Etnográfico e Paisagístico, pois o jardim toca dimensões históricas e artísticas presentes nos outros Livros.

No que tange às recomendações e legislações relacionadas ao conceito de paisagem cultural, apesar de as discussões internacionais a respeito datarem da década de 1990, a paisagem cultural somente foi abordada em uma carta patrimonial brasileira em 2007: a Carta de Bagé, elaborada entre os dias 13 e 18 de setembro durante o seminário "Semana do Patrimônio - Cultura e Memória na Fronteira", realizado na cidade de Bagé (RS). Também conhecida como "Carta da Paisagem Cultural" o documento objetiva a defesa das paisagens culturais, do território dos pampas e das paisagens culturais de fronteira. Em seu artigo 2, define o conceito de paisagem cultural como:

[...] o meio natural ao qual o ser humano imprimiu as marcas de suas ações e formas de expressão, resultando em uma soma de todos os testemunhos resultantes da interação do homem com a natureza e, reciprocamente, da natureza com homem, passíveis de leituras espaciais e temporais. (ICOMOS, 2007, p. 2).

No mesmo ano, entre 19 e 21 de setembro, no "Seminário Serra da Bodoquena/ MS - Paisagem Cultural e Geoparque" foi elaborada a Carta da Serra da Bodoquena, ou Carta das Paisagens Culturais e Geoparques. Apesar de centralizar as discussões em torno da preservação dos parques nacionais - com maior destaque para a serra da Bodoquena - encontra-se nesse documento uma definição de paisagem cultural e diretrizes para sua preservação:

[...] paisagens culturais e geoparques em última instância dizem respeito mais às pessoas que às coisas, uma vez que as premissas de conservação e preservação atendem à necessidade humana fundamental do conhecimento e do pertencimento a uma cultura e a um lugar. (CARTA DA SERRA DA BODOQUENA, 2007).

A questão da paisagem cultural no Brasil voltou a ser discutida com maior intensidade após a publicação pelo Iphan da Portaria n 127, de 30 de abril de 2009, que estabelece a chancela da Paisagem Cultural Brasileira. $O$ documento, entre outras considerações, afirma que o Brasil é "[...] autor de documentos e signatário de cartas 
internacionais que reconhecem a paisagem cultural e seus elementos como patrimônio cultural e preconizam sua proteção [...]" (BRASIL, 2009, p. 17) e que a Paisagem Cultural Brasileira se fundamenta na Constituição da República Federativa do Brasil de 1988'2. Considera ainda que a chancela da Paisagem Cultural Brasileira "[...] estimula e valoriza a motivação da ação humana que cria e que expressa o patrimônio cultural [...]" (BRASIL, 2009, p. 17), define o que se considera como Paisagem Cultural Brasileira (artigo $1^{\circ}$ ) e expõe qual a finalidade do estabelecimento da chancela (artigo $2^{\circ}$ ):

Art. $1^{\circ}$. Paisagem Cultural Brasileira é uma porção peculiar do território nacional, representativa do processo de interação do homem com o meio natural, à qual a vida e a ciência humana imprimiram marcas ou atribuíram valores. Art. $2^{\circ}$. A chancela da Paisagem Cultural Brasileira tem por finalidade atender ao interesse público e contribuir para a preservação do patrimônio cultural, complementando e integrando os instrumentos de promoção e proteção existentes, nos termos preconizados na Constituição Federal. (BRASIL, 2009, p. 17).

A definição de paisagem cultural por essa portaria, no entanto, não é específica, pois não apresenta o que seria a "porção peculiar do território" que exprime a interação humana com a natureza. Percebe-se que há uma indefinição no que diz respeito à escala, ao tamanho do que será chancelado, sendo aplicados os mesmos princípios tanto para um parque ecológico quanto para um pequeno jardim, revelando um conceito que engloba da microescala à macroescala, do determinado ao indeterminado sem considerar as especificidades de cada caso. Com certeza pode-se afirmar que os jardins históricos entram nessa categoria, embora a ausência de um conceito mais específico possa gerar dúvidas para a instauração de processos e o gerenciamento das políticas de preservação.

Apesar das discussões do tema da paisagem cultural, internacionalmente e mesmo no próprio Iphan, em outubro de 2010 foi elaborada a Carta dos Jardins Históricos Brasileiros, ou Carta de Juiz de Fora, estabelecendo definições, diretrizes e critérios para a defesa e salvaguarda dos jardins históricos brasileiros, mas sem incluí-los na perspectiva da paisagem cultural. Esse documento define jardim histórico como:

[...] os sítios e paisagens agenciados pelo homem como por exemplo, jardins botânicos, praças, parques, largos, passeios públicos, alamedas, hortos, pomares, quintais e jardins privados e jardins de tradição familiar. Além desses, jardins zoológicos, claustros, pomares, cultivos rurais, cemitérios, vias arborizadas de centros históricos, espaços verdes circundantes de monumentos ou centros históricos urbanos, áreas

12 No artigo 216 define-se: "Constituem patrimônio cultural brasileiro os bens de natureza material e imaterial, tomados individualmente ou em conjunto, portadores de referência à identidade, à ação, à memória dos diferentes grupos formadores da sociedade brasileira, nos quais se incluem: I - as formas de expressão; II - os modos de criar, fazer e viver; III - as criações científicas, artísticas e tecnológicas; IV - as obras, objetos, documentos, edificações e demais espaços destinados às manifestações artístico-culturais; $V$ - os conjuntos urbanos e sítios de valor histórico, paisagístico, artístico, arqueológico, paleontológico, ecológico e científico." (BRASIL, 1988). 
livres e espaços abertos em meio à malha urbana, entre outros. (CARTA DE JUIZ DE FORA, 2010, p. 1).

Após a definição a Carta de Juiz de Fora aborda a importância dos jardins históricos, a autenticidade e integridade, as problemáticas e os fatores de degradação, a identificação, proteção, preservação, conservação e manutenção, os aspectos gerais da gestão, os instrumentos de financiamento e fomento e as disposições finais. Mesmo abordando diferentes temas, o documento centra-se nas recomendações e diretrizes para manutenção e restauro de jardins semelhantes ao Manual Intervenções em Jardins Históricos, publicado pelo Iphan em 2005. Fica claro que as bases da Carta de Juiz de Fora se encontram nesse Manual, uma vez que nela se encontra a transcrição de vários trechos, alguns resumidos, outros iguais, da publicação do Iphan de 2005.

Ressalta-se que apesar de a aprovação da Carta dos Jardins Históricos Brasileiros ser muito positiva para a preservação dos jardins no país, não incluir a discussão da paisagem cultural no documento revela, à primeira vista, uma falta de diálogo no Instituto, já que a chancela da Paisagem Cultural Brasileira foi aprovada no ano anterior à elaboração da referida Carta.

\section{METODOLOGIAS PARA O RESTAURO DE JARDINS: ANÁLISE COMPARATIVA}

O restauro é definido atualmente pela Carta de Cracóvia como "[...] uma intervenção dirigida sobre um bem patrimonial, cujo objetivo é a conservação da sua autenticidade e a sua apropriação pela comunidade". (CARTA DE CRACÓVIA, 2000, s/p.). Apesar de essa Carta discorrer sobre os vários tipos de bens ${ }^{13}$, o estudo da prática do restauro sempre teve enfoque maior na recuperação das edificações de valor histórico.

No fim do século XIX e início do século XX, o tema da restauração desenvolveu uma conceituação diversa e mutável, e sua popularização encontra-se a partir das diferentes teorias propostas pelo francês Viollet-de-Duc, conhecidas como restauro estilístico, e posteriormente pelos italianos Camilo Boito, Gustavo Giovannoni e Cesare Brandi, cada qual com orientações distintas. Observa-se, contudo, que todos os principais métodos dessa temática são pensados para os monumentos arquitetônicos.

Portanto o que se tinha até então era uma adaptação das teorias de restauro arquitetônico para o jardim. Esse cenário muda em decorrência do aumento das discussões sobre os jardins históricos e a partir da criação do ICOMOS-IFLA, que divulga em 1989 uma metodologia de restauro de jardins históricos desenvolvida pela pesquisadora e paisagista Carmen Añón, membro do Comitê, intitulada O Jardim Histórico: notas para uma metodologia prévia ao projeto de recuperação.

Beriman (2011) ressalta a importância de Añón ao afirmar: "Doña Carmen estabeleceu uma metodologia de estudo e restauração dos jardins históricos que converteu

13 Citam-se o patrimônio arqueológico, monumentos e edifícios com valor histórico, decoração arquitetônica, escultura e elementos artísticos, cidades e aldeias históricas, paisagens e técnicas de conservação. 
em modelo." (BERJMAN, 2011, p. 33). Em sua proposta metodológica, Añón (1989) amplia a definição de jardim histórico da Carta de Florença reconhecendo sobretudo o valor documental das obras paisagísticas. $\bigcirc$ jardim histórico é definido como:

[...] uma criação espacial em que os elementos arquitetônicos e os elementos vegetais formam uma unidade inseparável, constituindo-se como um importante documento histórico, uma forma de grande valor estético, uma expressão de características indubitavelmente espirituais. (AÑóN, 1989, p. 312).

Añón (1989) também ressalta a importância de desenvolver uma metodologia específica para os bens paisagísticos. $\bigcirc$ modelo proposto por Añón influencia até hoje as metodologias de restauro em jardins desenvolvidas em todo o mundo, incluindo a proposta brasileira publicada pelo Iphan em 2005, "Manual de Intervenções de Jardins Históricos", de Carlos Moura Delphim ${ }^{14}$ - a primeira obra publicada no país que trata exclusivamente sobre a restauração de jardins.

Recuperando muitos aspectos propostos por Añón e propondo outros, Delphim (2005) tem outra concepção de jardim histórico, não o vendo como um documento, mas como um bem cultural em constante mutação. Para ele o jardim é "[...] um bem cultural que apresenta valores culturais, socioeconômicos e ambientais que, ao longo de diferentes fases de evolução, foram sofrendo transformações e adquirindo novos e dinâmicos significados". (DELPHIM, 2005, p. 17).

A partir das diferentes conceituações de jardim histórico de ambos autores, a de Añón (1989), exaltando o valor documental do jardim, e a de Delphim (2011), evidenciando-o como um bem cultural, propõe-se um comparativo entre seus trabalhos. A escolha do método de Añón e do método de Delphim se justifica na medida em que são divulgados por importantes órgãos de preservação internacional (ICOMOS) e nacional (Iphan). A estruturação desses métodos é ilustrada na tabela 3.

Como pode ser observado na tabela 3, o método de Añón (1989) propõe quatro fases para o desenvolvimento de uma intervenção futura: 1) análise histórica, que além da descrição do jardim abrange toda a sua documentação histórica; 2) estado atual, que tem a função de mostrar a integridade física em que o jardim se encontra; 3) estudo paisagístico, que se refere ao projeto paisagístico em si, incluindo a parte construída e a parte viva (espécies de plantas); 4) critérios de restauração em que se estabelecem quais princípios devem ser considerados, evidenciando os mais e menos relevantes num projeto de restauro de jardim histórico.

14 Integrante da Comissão Nacional de Sítios Geológicos e Paleobiológicos desde 2000. Representante-Titular do Iphan na Comissão Nacional de Recursos Hídricos. Membro da Representação do Brasil na Comissão de Patrimônio Mundial da UNESCO. Coordenador-Geral de Patrimônio Natural do Departamento de Patrimônio Material e Fiscalização do Iphan. 
Da Preservação à Restauração: Políticas e Métodos Aplicados aos Jardins Históricos

Tabela 3 Tabela mostrando o comparativo das metodologias de intervenção em jardins históricos

\begin{tabular}{|c|c|}
\hline AÑÓN (1989) - ICOMOS-IFLA & DELPHIM (2005) - IPHAN \\
\hline 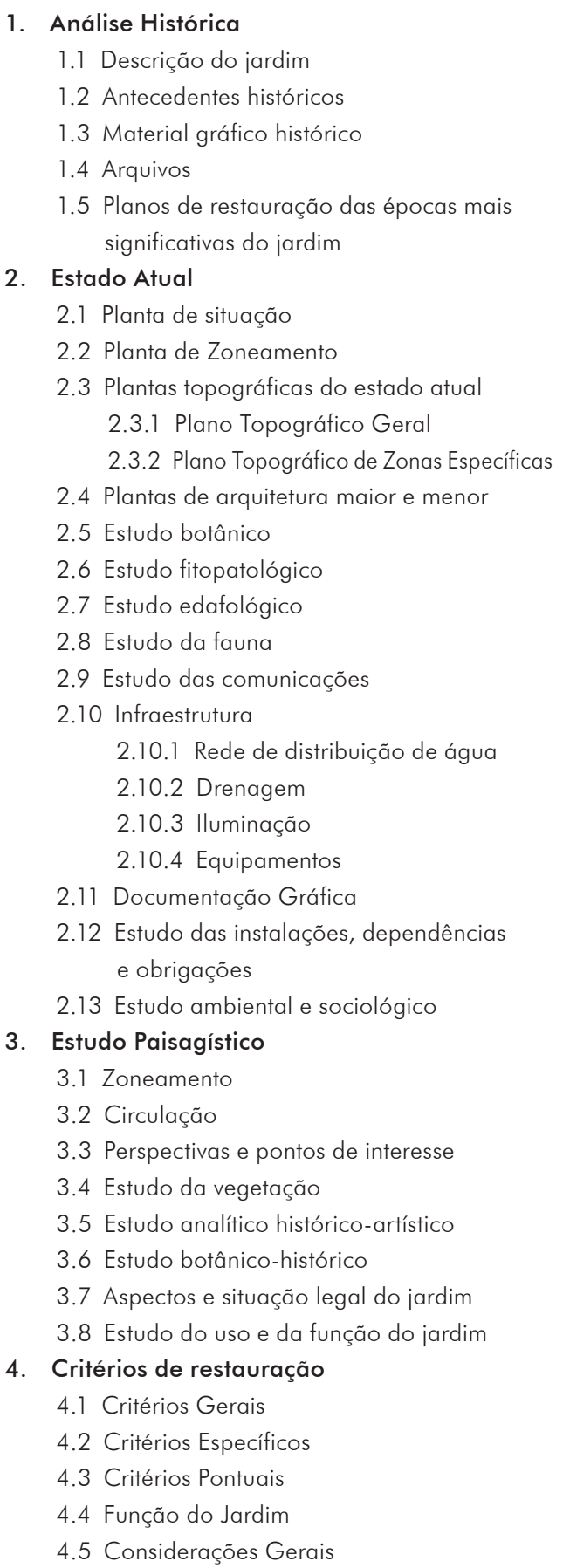 & $\begin{array}{l}\text { Operações de Preservação } \\
\text { Identificação } \\
\text { Localização } \\
\text { Dados cartoriais e jurídicos } \\
\text { Informações sobre o meio físico } \\
\text { Levantamento edáfico } \\
\text { Informações sobre o meio biológico } \\
\text { Informações sobre o meio antrópico } \\
\text { Pesquisa histórica } \\
\text { Pesquisa bibliográfica } \\
\text { Informações de arquivo } \\
\text { Pesquisa iconográfica } \\
\text { Investigação arqueológica } \\
\text { Entrevistas } \\
\text { Registro fotográfico } \\
\text { Representação gráfica: meios físico, biológico } \\
\text { e antrópico } \\
\text { Planejamento } \\
\text { Proteção } \\
\text { Conservação } \\
\text { Restituição } \\
\text { Restauração } \\
\text { Revitalização } \\
\text { Manutenção } \\
\text { Administração } \\
\text { Uso } \\
\text { Intervenções em jardins históricos } \\
\text { Circulação } \\
\text { Iluminação } \\
\text { Sinalização } \\
\text { O Jardim como ecossistema } \\
\text { Vegetação } \\
\text { Fauna } \\
\text { Roteiro para elaboração de projetos } \\
\text { Levantamento } \\
\text { Projeto definitivo }\end{array}$ \\
\hline
\end{tabular}

Fonte: Elaborada por Marianna Gomes Pimentel Cardoso sobre os métodos propostos por Añón (1989) e Delphim (2005). 
Añón (1989) afirma que na análise e documentação o objetivo é conhecer profundamente o jardim por meio do estudo do seu passado e seu presente, estabelecendo dessa forma um duplo contato físico e espiritual com o jardim para tentar alcançar sua profunda razão de ser, unida ao pleno conhecimento do seu estado atual e das suas possibilidades. A partir da segurança fornecida pelas investigações realizadas, podem-se estabelecer os critérios que vão determinar o projeto e as linhas gerais de atuação, analisando os pontos conflituosos e buscando as soluções mais adequadas.

Determinados os critérios, Añón (1989) inclui o desenvolvimento completo do projeto, determinando fases de realização, pressupostos parciais e totais. Posteriormente estabelece uma política de manutenção determinada a obter a imagem final do jardim e ações complementares adequadas para os diferentes casos, buscando potencializar o jardim e assim desenvolver a missão cultural que lhe é inerente ao assegurar sua conservação.

Somente estudando cada uma das partes propostas "[...] podemos passar a considerar o jardim como um 'todo' em uma unidade temporal e estilística". (AÑÓN, 1989, p. 323). É importante destacar que a autora estabelece essa metodologia como ponto de partida, podendo sofrer inclusões de outros tópicos sempre necessários. Também inclui a importância do trabalho em equipe, pois o restauro de jardins é " [...] sempre um projeto interdisciplinar onde é necessário coordenar diversas técnicas e especialidades para um bom desenvolvimento". (AÑóN, 1989, p. 312).

Outro fato importante ressaltado na proposta da autora é a proposição de quatro ideias fundamentais em toda a restauração de jardim: ser fiel à sua origem, respeitar a passagem do tempo, valorizar contribuições e evitar dissonâncias. Esta afirma que todo elemento dissonante estética ou historicamente deve ser evitado, mas diante de uma dúvida estética-histórica prioriza-se sempre o estético sobre o histórico, pois no jardim deve-se encontrar harmonia. Ao colocar o valor estético em primeiro lugar, nota-se que apesar de Añón exaltar o valor documental do jardim tem em seu íntimo que o mesmo corresponde a uma obra de arte.

Quanto à proposta brasileira de uma metodologia de restauro, recorre-se ao Manual de intervenções em jardins históricos. Nele Delphim (2005) traça um breve histórico dos jardins brasileiros, apresenta trechos da Carta de Florença - sob o título de "A preservação dos jardins históricos" - e posteriormente, de maneira panorâmi$\mathrm{ca}$, alguns conceitos das teorias de restauração e conservação. Sem aprofundar e sem citar autores e obras aos quais se refere, o autor define os significados de valor, integridade e autenticidade dos bens a serem preservados.

Após essa introdução, o autor descreve as operações de preservação que devem ser consideradas nas intervenções: identificação, planejamento, proteção, conservação, restituição, restauração, revitalização, manutenção, administração e uso. No Manual, Delphim (2005) estabelece parâmetros para a circulação, iluminação e sinalização inseridas em um jardim histórico. No tópico "O jardim como ecossistema" discorre sobre a integração da vegetação com a fauna e os cuidados específicos para ambas 
em um jardim histórico. Por fim propõe um "Roteiro" para elaboração de projetos que não apresenta muitas novidades para arquitetos e projetistas.

Como nota-se no título do Manual, a palavra usada é "intervenção" e não "restauro". O uso do termo justifica-se pelo fato de Delphim (2005) trabalhar com várias noções de intervenção, como a conservação e a preservação. Outro aspecto importante de sua obra está no fato de denominar a metodologia proposta como "recomendações", o que tem repercussão direta na forma como é estruturado seu discurso. Não há um estabelecimento de etapas rigidamente pontuadas como se vê no método do ICOMOS-IFLA, e sim pontos a serem considerados em uma intervenção.

Segundo Delphim (2005), o Manual de intervenção em jardins históricos faz parte de um conjunto de manuais editados pelo Iphan com objetivo de atender às exigências de orientação técnica voltadas para a conservação e preservação dos jardins históricos sob tutela federal (DELPHIM, 2005, p. 7). Ao contrário do método de Añón (1989), que possui abordagem mais científica, problematizando e fazendo reflexões em cada tópico, Delphim (2005) apresenta uma abordagem mais prática e menos crítica.

Os autores destinam propostas a públicos diferentes: Añón dirige-se ao leitor especializado, ciente das temáticas que envolvem o jardim, adotando um discurso mais científico; Delphim inclui o leigo, descrevendo noções temáticas básicas e adotando uma linguagem que permite entender mais facilmente suas colocações. $\bigcirc$ próprio autor afirma que sua obra:

[...] se destina a técnicos do IPHAN, dos órgãos estaduais e administrativos municipais ou profissionais liberais envolvidos na preservação, empresas de restauração, proprietários e usuários de espaço de valor cultural que estejam submetidos a qualquer forma de proteção. (DELPHIM, 2005, p. 7).

Nos textos dos dois autores encontram-se passagens que valorizam a interdisciplinaridade nos trabalhos em jardins, reconhecendo que estes incorporam várias dimensões. Ambos reconhecem que todas as questões propostas exigem complementações permanentes.

Constata-se que o método de Añón (1989) possui organização mais rigorosa dos pontos estudados e adota uma divisão mais bem estruturada em relação à adotada por Delphim (2005) - que estende suas discussões para questões de manutenção, administração e acessibilidade. Mesmo constatando que o método de Ãnón se revela mais elaborado, tanto este quanto o de Delphim cumprem o que é proposto, pois voltam-se a públicos diferentes e objetivos distintos.

\section{CONSIDERAÇÕES FINAIS}

A atual política patrimonial, tanto no cenário nacional como internacional, apresenta discussões e formulações ainda recentes e em constantes transformações. No Brasil 
nota-se que as diferentes compreensões sobre o jardim histórico originam classificações distintas ou até mais atribuições de valor para um mesmo tipo de objeto.

A respeito do restauro dos jardins observou-se, por meio das metodologias apresentadas, a complexidade dos jardins históricos, demandando para qualquer intervenção equipes compostas por diferentes profissionais, técnicos com as mais diversas formações (entre outros) e intensa pesquisa envolvendo a parte construída - artística, arquitetônica - e a parte viva, a vegetação.

Durante este estudo foi realizada uma entrevista ${ }^{15}$ com o filósofo dr. Jacques Leenhardt, diretor da Escola de Altos Estudos em Ciências Sociais Paris-França (EHESS) e autor da obra Nos jardins de Burle Marx. Ao questioná-lo a respeito da sua compreensão sobre o tratamento do jardim no âmbito do patrimônio, afirmou: "É uma questão interessante e difícil também, porque o jardim é um ente vivo". Completou que o jardim pode ser estudado sob o viés da composição, do seu traçado, da sua dinâmica própria ao que é vivo, portanto em transformação constante, podendo a estética adaptar-se a novas concepções. E concluiu honesta e despretensiosamente, dizendo: "Acho que não tenho um posicionamento definido. É algo muito recente...".

De fato, os impasses para definir e classificar os jardins históricos, que variam entre seu tratamento como monumento até como paisagem cultural, evidenciam a importância de discutir o tema e estabelecer melhores critérios para a preservação desse tipo de patrimônio.

\section{REFERÊNCIAS BIBLIOGRÁFICAS}

AÑÓN, Carmen. El jardín histórico: notas para una metodología previa al proyecto de recuperación, 1989, p. 312 325. In: ICOMOS-UNESCO, Journal scientifique: jardins et sites historiques, Fundación Cultural Banesto. Ed. Doce Calles, 1993. Disponível em: <www.icomos.org/publications/journal_scientifiquel/js1_jardins_historiques. pdf>. Acesso em: 11 nov. 2012.

ARAÚJO, Guilherme Maciel. Paisagem cultural: um conceito inovador. In: CASTRIOTA, Leonardo Barci. Paisagem cultural e sustentabilidade. Belo Horizonte: UFMG: IEDS, 2009. 1 DVD (Arquitetura \& Cidade).

BERJMAN, Sonia. Quieren preservar los jardines históricos como patrimonio cultural. Clarín.com. 2001. Disponível em: <http://edant.clarin.com/diario/2001/10/19/s-05201.htm>. Acesso em: 20 out. 2010.

. De los jardines históricos a los paisajes culturales: la labor de ICOMOS através del tempo. In: SIMPÓSIO ARQUEOLOGIA NA PAISAGEM: UM OLHAR SOBRE OS JARDINS HISTÓRICOS, 2, 201 1, Rio de Janeiro, Universidade Federal do Rio de Janeiro, Escola de Belas Artes, 2011.

BERTRUY, Ramona Pérez. Estudio introductorio a los temas mexicanos. In: CARNEIRO, Rita Sá; BERTRUY, Ramona Pérez (Org.). Jardins históricos brasileiros e mexicanos. Recife: Editora Universitária UFPE, 2009.

(Org.). Jardins históricos brasileiros e mexicanos. Recife: Editora Universitária UFPE, 2009.

BRASIL. Decreto-Lei No 25 de 30 de novembro de 1937. Organiza a proteção do patrimônio histórico e artístico nacional. Diário Oficial da União, 6 dez. 1937, p. 24056.

. Constituição (1988). Constituição da República Federativa do Brasil. Promulgada em 5 de outubro de 1988. Disponível em: <http://www.planalto.gov.br/ccivil_03/Constituicao/Constituicao.htm>. Acesso em: 10 jul. 2012.

15 Entrevista concedida durante o V Simpósio de História Cultural Brasília 50 anos: ler e ver paisagens subjetivas e paisagens sociais, 8 nov. 2010, Brasília. 
Portaria 217, 2009. Estabelece a Chancela da Paisagem Cultural Brasileira. Diário Oficial da União, $n^{\circ}$ 83, 5 mai. 2009, Seção 1, p. 17.

CARDOSO, Marianna Gomes Pimentel. O jardim como patrimônio: a obra de Burle Marx em Brasília. 2012. 189 f. Dissertação (Mestrado em Arquitetura e Urbanismo) - Universidade de Brasília, Brasília, 2012.

CARTA DA SERRA DA BODOQUENA. 2007. Disponível em: <http://portal.iphan.gov.br/portal/baixaFcdAnexo. do? $\mathrm{id}=1112>$. Acesso em: 10 jul. 2012.

CARTA DE ATENAS. (1931). In: CURY, Isabelle (Org.). Cartas Patrimoniais. Iphan. Rio de Janeiro: Edições do Patrimônio, 2000.

CARTA DE CRACÓVIA. Princípios para a conservação e o restauro do património construído. 2010. Disponível em: <http://www.igespar.pt/media/uploads/cc/cartadecracovia2000.pdf>. Acesso em: 10 jul. 2012.

CARTA DE FLORENÇA. (1981). In: CURY, Isabelle (Org.). Cartas Patrimoniais. Iphan. Rio de Janeiro: Edições do Patrimônio, 2000.

CARTA DE VENEZA. (1964). In: CURY, Isabelle (Org.). Cartas Patrimoniais. Iphan, Rio de Janeiro. Edições do Patrimônio, 2000.

CARTA DOS JARDINS HISTÓRICOS. CARTA DE JUIZ DE FORA. 2010. Disponível em: < http://portal.iphan.gov.br/ baixaFcdAnexo.do;isessionid=3D52CDFD271 ACC123EEBD3C8E284FDB1 ? id=2510 >. Acesso em: 20 fev. 2010

CASTRIOTA, Leonardo Barci. Paisagem cultural e sustentabilidade. Belo Horizonte: UFMG: IEDS, 2009. 1 DVD (Arquitetura \& Cidade).

Patrimônio cultural: conceitos, políticas, instrumentos. São Paulo: Annablume, 2010.

CAUQUELIN, Anne. A invenção da paisagem. São Paulo: Martins Fontes, 2007.

CHOAY, Françoise. As questões do património. Lisboa: Edições 70, 2011.

DELPHIM, Carlos Fernando de Moura. Manual de intervenções em jardins históricos. Brasília: Iphan, 2005.

FARIELLO, Francesco. La arquitectura de los jardines: de la antigüedad al siglo XX. Barcelona: Reverte, 2008.

ICOMOS. Conselho Internacional de Monumentos e Sítios. Jardins et Sites historiques, Journal Scientifique, 1993. Disponível em: <www.icomos.org/publications/journal_scientifiquel/is1_jardins_historiques.pdf>. Acesso em: 26 mar. 2011.

Carta de Bagé ou Carta da Paisagem Cultural. 2007. Disponível em: <http://www.icomos.org.br/

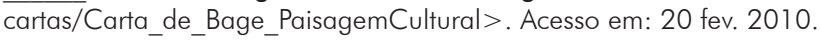

IPHAN. Instituto do Patrimônio Histórico e Artístico Nacional. Lista de Bens Tombados e Processos em Andamento (1938 - 2015). Disponível em: <http://portal.iphan.gov.br/uploads/ckfinder/arquivos/Lista\%20 Bens\%20Tombados\%20Dez\%202015.pdf>. Acesso em: 12 jan. 2015.

MARCKE, Annie van. Presente en la creación. Disponível em: <http://www.icomos.org/landscapes/Presente\%20 en\%20la\%20Creaci\%F3n.pdf>. Acesso em: 12 mar. 2012.

MARCONDES, Maria José de A. Modernismo e preservação: jardins históricos e valor documental. In: CARNEIRO, Ana Rita Sá; BERTRUY, Ramona Pérez (Org.). Jardins históricos brasileiros e mexicanos. Recife: Editora Universitária da UFPE, 2009.

RIBEIRO, Rafael Winter. Paisagem cultural e patrimônio. Brasília: Iphan, 2007.

VIEIRA, Daniel de Souza Leão. Paisagem e imaginário: contribuições teóricas para uma história cultural do olhar. Revista de História e Estudos Culturais, vol. 3, ano 3. Disponível em: <http://www.revistafenix.pro.br/PDF8/ DOSSIE-ARTIGO7-Daniel.Souza.Leao.Vieira.pdf>. Acesso em: 20 fev. 2011. 